\title{
Erratum to: Electrochemical nanogravimetric study on the sorption processes occurring in multiwalled carbon nanotube layers immobilized on a gold surface
}

Colin E. Moore • György Inzelt

Published online: 25 June 2014

(C) Springer-Verlag Berlin Heidelberg 2014

Erratum to: J Solid State Electrochem

DOI 10.1007/s10008-014-2532-x

The original version of the article, unfortunately, contained a mistake in Fig. 9. The correct unit of the frequency difference on the y-axis is $\mathrm{Hz}$ and not $\mathrm{kHz}$.

The online version of the original article can be found at http://dx.doi.org/ 10.1007/s10008-014-2532-x.

C. E. Moore $\cdot$ G. Inzelt $(\triangle)$

Department of Physical Chemistry, Institute of Chemistry, Eötvös

Loránd University, Pázmány Péter sétány 1/A, 1117 Budapest,

Hungary

e-mail: inzeltgy@chem.elte.hu 